\title{
The impact of trait introversion-extraversion and identity on state authenticity: Debating the benefits of extraversion
}

\author{
Isabella R. L. Bossom \& John M. Zelenski \\ Carleton University
}

A copyedited version of this manuscript appears in the Journal of Research in Personality.

Bossom, I. R. L., \& Zelenski, J. M. (2022). The impact of trait introversion-extraversion and identity on state authenticity: Debating the benefits of extraversion. Journal of Research in Personality, 97, 104208.

Materials, data, etc. at https://osf.io/nbzkw/

Contact:

John M. Zelenski

Department of Psychology

Carleton University

1125 Colonel By Drive

Ottawa, ON K1S 5B6

Canada

email: john_zelenski@carleton.ca

Draft dated Feb. 25, 2022 


\begin{abstract}
Research suggests that trait introverts feel more authentic when acting extraverted. We explored boundaries of this idea by assessing trait and identities as introvert or extravert and asking participants to debate extraversion's value. Students (Study 1: $N=310$, Study 2 direct replication: $N=407$ ) were randomly assigned to pro or con sides in the debate and then reported their state authenticity and affect. Results suggested interactions between individual differences (trait, identity) and debate condition on authenticity. Counter-dispositional and counter-identity debating decreased authenticity, though with variation in strength across studies. Affect did not follow this pattern. These findings provide preliminary evidence for the importance of traitrelated identities and suggest limits to the benefits of embracing counter-dispositional extraversion.
\end{abstract}

Keywords: Extraversion; Authenticity, Beliefs, Values, Social Identity, Well-being 


\section{Introduction}

The construct of authenticity connotes living in ways that represent the true self, and it is considered a hallmark of psychological well-being (Schlegel \& Hicks, 2011). Moment-tomoment variations in state authenticity are positively associated with value-consistent behavior, self-esteem, and positive moods (Sedikides et al., 2017). However, some correlates and experiments challenge the notion that state authenticity follows from the expression of important personality characteristics. For example, people who are dispositionally introverted often report feeling more authentic and happier during the moments they act in extraverted ways (Fleeson \& Wilt, 2010). Trait-inconsistent extraverted behavior may feel authentic because it can simultaneously facilitate other personally important goals or roles such as getting a date or being a good host. Still, at least some introverts seem to bristle at the idea that extraverted behavior benefits them (cf. aspects of Cain's [2012] 'quiet revolution' and see Lawn et al., 2018), even while empirical work tilts strongly towards the momentary benefits of extraverted behavior. Here we present a study and direct replication that explores limits to the strong link between extraversion and authenticity. First, we introduce the idea that introversion-extraversion as a trait can be somewhat independent of its importance as an identity. Whereas some introverts may commit themselves to the quiet revolution as passionately as introverts do anything, others may simply possess the trait while seeing other elements of their personalities as more central and personally important. Additionally, we test the introvert identity construct in a context that might press the limits of introverts' contra-trait tolerance: debating for or against the value of extraversion directly. In essence, will introverts, or a subset of highly identified introverts, still feel authentic when arguing for the benefits of extraversion? 
From ancient philosophers to contemporary humanistic and positive psychologists, living in accordance with one's true self — authentically_is seen as desirable (Rivera et al., 2019). Authenticity is often characterized as a facet of eudaimonic well-being or flourishing, and then contrasted with hedonic well-being. Whereas hedonic well-being is characterized by pleasant feelings and the absence of pain, eudaimonic well-being encompasses a broader set of advantageous characteristics such as virtuous behavior, meaning, personal growth, and authenticity (Huta \& Waterman, 2014). Importantly, authenticity, like other elements of eudaimonia, is valued independent of its potential associations with feeling good. Referencing authentic behavior against an objectively defined true self is difficult or impossible, and contemporary assessments typically rely on self-reports and subjective impressions of authenticity. Trait authenticity scales tap things like people's sense of accurate self-knowledge, independence from external influence, and sincerity (Wood et al., 2008; Kernis \& Goldman, 2006). In the abstract, authentic behavior might represent accurate yet undesirable and destructive facets of people, but empirically, and consistent with humanistic approaches, people typically see their and others' true selves as good (Strohminger et al., 2017). Accordingly, reports of authenticity correlate robustly with a variety of other well-being indicators including self-esteem, positive affect, life satisfaction, purpose in life, etc. (see recent review by Rivera et al., 2019). Recently, more research has turned to state authenticity (feeling true to oneself 'right now'), and these reports are also associated with a wide variety of other desirable momentary ratings such as pleasant affect, self-esteem, and meeting basic needs for autonomy, competence, and relatedness (Heppner et al., 2008; Sedikides et al., 2017).

Even with the consistent associations between authenticity and well-being measures, other findings raise intriguing questions about the construct validity of authenticity measures and 
what it means to behave in accordance with the (true) self. On the more supportive side, state authenticity is associated with value-consistent behavior (Smallenbroek et al., 2017) and moral behavior (Christy et al., 2016). State authenticity’s positive associations with intrinsic motivation, need satisfaction, positive affect, self-esteem, etc., form an internally consistent argument within self-determination theory because it further assumes a positive, self-directed human nature (Sheldon et al., 1997). On the other hand, laboratory studies show that incidental positive affect manipulations can increase authenticity ratings (Lenton et al., 2013) and that authenticity ratings seem biased towards pleasant behaviors, beyond the actual self-congruence of those behaviors (Jongman-Sereno \& Leary, 2020; Smallenbroek et al., 2017). Another important challenge to the notion that state authenticity follows from self-consistent behaviors comes from studies which match momentary behaviors or roles to broad personality traits, such as the Big Five or HEXACO taxonomies. Across many studies, there is scant evidence that behaving in a way that matches dispositions (e.g., dispositional introverts sitting quietly) produces authenticity; rather, behaving in more socially desirable ways, extraverted, stable, conscientious, agreeable, open, and honestly, predicts feelings of authenticity regardless of disposition (Ching et al., 2014; Cooper et al., 2018, Fleeson \& Wilt, 2010; Leikas et al., 2021; Whelan, 2013). When behavior and authenticity are measured concurrently, dispositional introverts report feeling more authentic when behaving in extraverted ways (as do extraverts).

At first glance, the common experience of authentic trait-incongruent behaviors seems like a challenge to the notion that authenticity accurately represents expressions of the true self. However, this is not the typical conclusion of these papers, and it depends on the dubious assumption that people's broad traits are important elements of their true selves. Contemporary views of personality, clearly supported by data, recognize that people's behavior varies 
frequently and broadly moment-to-moment, while also showing clear mean level differences between-persons, which we understand as traits (Fleeson, 2004). Although dispositional introverts behave in both introverted and extraverted ways over time, they engage in introverted behaviors more frequently than dispositional extraverts do. As such, counter-dispositional behavior is still normative if somewhat less frequent. Moreover, this behavioral variation likely follows, at least in part, from personally important desires. For example, both introverts and extraverts typically behave in extraverted ways when they are trying to be a leader, be interesting, or convey information (McCabe \& Fleeson, 2012). Particular contexts also pull for behaviors (e.g., library vs. party), and although somewhat external as an influence, violating social norms to better represent one's average behavior (trait) does not seem like an important imperative of the true self. In other words, introverts can feel authentic when behaving in extraverted ways because it helps them get along and meet other personally important goals.

Traits do not seem like sacred elements of personality that produce inauthenticity when transgressed. However, other personality features, such as values, do seem to require more consistency for high state authenticity (Smallenbroek et al., 2017). Whereas an introvert might enthusiastically tell a story to her in-laws with no authenticity cost, appeasing their outdated attitudes with racist jokes is likely quite different. As a middle ground between merely descriptive characteristics (traits) and moral guides (values), people's self-concepts and social identities are personally important, and they likely influence the dynamics between self-behavior fit and authenticity (Schmader \& Sedikes, 2018). Moreover, we argue that people can have selfconcepts and social identities about their traits. Whereas some dispositional introverts may not see the trait as important to their sense of self (i.e., just one of many characteristics they have), others may embrace their introversion as a defining feature of the self and feel camaraderie with 
other introverts. We suspect that introversion may be increasingly important to some people, particularly as a social identity, in the wake of Susan Cain's 'Quiet Revolution' which began with a popular book and TED talk about valuing introversion and grew to a substantial movement with active online communities and targeted marketing (Cain, 2012). Among these highly identified introverts, extraverted behavior may create more tension with state authenticity than has been observed to this point, at least in some contexts.

To test these ideas, we assessed people's strength of identification as an introvert or extravert in the framework of social identity theory. Social identity theory posits that social identities are the aspects of people's self-views that come from the social groups and categories they perceive they are members of (Tajfel, 1978; Tajfel \& Turner, 1979). Common examples include gender, ethnicity, and religion, but social identities can include any perceived social group. Strongly identified people tend to feel similarity and closeness with other ingroup members and often denigrate outgroup members. Stronger social identities are also represented by a sense of importance, compared to weak identities' relative indifference towards group membership. In the present research, we adapted a common measure of social identity (Cameron, 2004) to assess the major components of social identity (i.e., ingroup ties, centrality to the selfconcept, and ingroup affect) for both introverts and extraverts. We anticipated that identification would be distinct from the trait itself, and then only modestly correlated. We also explored some other beliefs that people can have around their traits which were studied in the context of authenticity by Lawn et al. (2019), for example , wanting to be more/less extraverted or believing extraversion is valued in your culture.

We also adapted a debate procedure from Smallenbroek et al. (2017), who found that being randomly assigned to argue for the value of benevolence produced substantially more 
authenticity than arguing against, and especially for people who prioritized benevolence over other values. We suspect that social identity falls somewhere between values and traits in terms of determining what is personally correct and authentic. As such social identities may produce authenticity differences in the debate procedure which has shown clear 'counter-values' effects on authenticity. In our adaptation here, participants were randomly assigned to argue for or against the value of extraversion. Although valuing or arguing for extraversion is not the same as extraverted behavior per se, we thought it would draw a sharp contrast between people who cared and did not care much about having this trait, i.e., stronger vs. weaker social identities. Also, the debate resolution was phrased to argue for or against the benefits of extraversion, rather than introversion because extraversion is typically preferred and may differ from introversion in the possible stigma that exists. That is, we approached this research thinking about introverts who may bristle at the 'extraversion ideal' (Cain, 2012) and phrased the debate accordingly. The mirror situation (i.e., trait extraverts' arguing for the benefits of introversion) may not be equivalent, and is not directly addressed in this research.

We predicted that strongly identified introverts would feel less authentic when arguing for (vs. against) the benefits of extraversion. We also predicted that this same pattern would be weaker or null for the trait measure of introversion-extraversion itself. The other belief measures, taken from Lawn et al.'s (2018) paper, were much more exploratory, but we reasoned that having more pro-extravert beliefs (desire to be extraverted, seeing cultural bias towards extraversion) might make arguing for the trait feel more authentic too. Finally, we also assessed affect. We anticipated that the fit between debate condition and individual differences would matter more for authenticity than affect. Although state authenticity and positive affect co-vary, our manipulation is designed to target fit with individual differences; such results would further 
suggest that there is more to authenticity than merely feeling good. We report how we determined our sample size, all data exclusions, all manipulations, and all measures in the study. Materials and data are available at:

https://osf.io/nbzkw/?view_only=80149e469f484f028b13580bc16ff2cc

Study 1: Extraversion values study

\section{Method}

\section{Participants}

Canadian students $(\mathrm{n}=402)$ enrolled in first and second year psychology courses were recruited in Winter 2020 online from the university's research portal for a study titled 'Debating the Value of Introversion/Extraversion'. Based on pragmatic concerns and rules of thumb, we endeavored to recruit at least 300 participants, and ended data collection at the end of the term. Prior to hypothesis testing, 42 participants were excluded because they spent less than 10 or more than 75 minutes on the study, 17 participants were excluded for missing data, and 33 participants, who had not already been excluded for time or missing data reasons, were excluded for inadequate response attempts on the simulated debate task. Of the remaining 310 participants, the majority were female (78.4\%) and the mean age was 19.94 . With our sample size, we have $80 \%$ power to detect an ANOVA interaction with $\eta_{p}{ }^{2}=.025$, an interaction in the full sample regressions with $\Delta R^{2}=.025$, and an interaction in the smallest subsample (extraversion identity, $n=117$ ) of $\Delta R^{2}=.063$ (see supplement for details of sensitivity analyses).

\section{Procedure and materials}

\section{Procedure}


This research has been approved by the university ethics board \#111876. The study was conducted online using Qualtrics. Informed consent was obtained before the study began. Participants first completed questionnaires measuring their traits, social identity as introverts or extraverts, culture preference for extraversion, perceived pressure to display extraversion, and extraversion-deficit beliefs. Then, participants were randomly assigned to debate that it is good to be more extraverted than introverted in either a pro-extraversion or con-extraversion condition. Next, participants completed questionnaires on state authenticity and effort, their debate experience (e.g., agreement with assigned position), state affect, life satisfaction, and trait affect. Then, a textbox was provided prompting participants to indicate, if they wished, their true beliefs about extraversion to relieve any possible tension from the assigned debate position. Finally, demographic information was collected. Participants were debriefed upon study completion.

\section{Traits}

Traits were assessed using an adapted version of the short Big-Five Personality Inventory-2 (Soto \& John, 2017). Participants were asked to rate the degree to which they agreed with 36 statements relating to the opening phrase 'I see myself as someone who...', on a 5-point Likert scale. Each trait scale contained six items, except for extraversion $(a=.86)$, which included an additional six items from the longer BFI-2.

\section{Social identity of introversion or extraversion}

Introverted and extraverted social identities were assessed using a three-factor model of social identity (Cameron, 2004). Initially, participants were asked to indicate whether they believed they are an introvert $(n=193$; pro-extraversion condition $=108$, con-extraversion condition $=85)$ or extravert $(n=117$; pro-extraversion condition $=50$, con-extraversion 
condition $=67$ ) based on their current understanding of the term definitions. Then, based on the term they selected, they indicated the degree to which they agreed with 12 statements on a 7point Likert scale. We focus on the full scale for introversion $(a=.69)$ and extraversion $(a=$ .77), though three subscales are also scored: ingroup ties (for introversion $a=.70$, for extraversion $a=.74$, centrality (for introversion $a=.76$, for extraversion a $=.66$ ), and ingroup affect (for introversion $a=.87$, for extraversion $a=.72$ ).

\section{Cultural value of extraversion}

The cultural value of extraversion was measured as described by Lawn et al., (2018). Participants rated how valued 4 typically introverted and 4 typically extraverted traits are in society. The adjectives demonstrated acceptable internal consistency, specifically introverted items, $a=.75$, and extraverted items, $a=.77$. Scores were calculated by subtracting the averaged introverted items from the averaged extraverted items.

\section{Perceived pressure to display extraversion}

The perceived pressure to display extraversion was also measured as described by Lawn et al., (2018). Participants rated how often in the past month they believed it was necessary to display 4 typically introverted and 4 typically extraverted traits in public. The adjectives demonstrated questionable internal reliability respectively, specifically introverted items, $a=.54$, and extraverted items, $a=.65$. A similar subtraction created an index of perceived pressure to display extraversion over introversion.

\section{Extraversion-deficit beliefs}

Extraversion-deficit beliefs were measured using two statements regarding participants' perceived actual versus ideal levels of introversion or extraversion as described by Lawn et al., 
(2018). An index of extraversion-deficit beliefs was computed by subtracting participants' actual scores from their ideal scores, with higher scores indicating a desire to be more extraverted.

\section{Simulated debate}

Participants were instructed to participate in a simulated debate on the topic of the value of introversion and extraversion, which followed the same structure as that of Smallenbroek et al., (2017). All participants debated the resolution 'it is good to be more extraverted than introverted'. Participants were randomly assigned to either a pro-extraversion condition $(n=$ 158), arguing for the resolution indicating that it is good to be more extraverted than introverted, or con-extraversion condition $(n=152)$ arguing against the resolution. In total, there were six rounds of debate. In the first round, participants were instructed to provide one brief argument supporting their position. Then an opposing argument appeared that participants were instructed to rebut by providing a novel brief argument supporting their position. There were four rounds of rebuttals after the initial argument. Finally, participants were asked to summarize their arguments for their assigned position and were encouraged to provide any additional novel arguments to strengthen their position. After data collection, coding was performed on the debate responses to ensure participants were meeting the task demands for their assigned condition. Participants were coded as either having provided adequate, potentially adequate or inadequate responses based on having provided at least three out of six responses that complied with the task demands. Of the 402 participants collected in the study, data from 331 were considered adequate, 17 were considered potentially adequate, and 54 were inadequate. Data coded as potentially adequate and adequate were included in our analyses.

\section{State authenticity and effort}


State authenticity was assessed via 10 items compiled and adapted by Whelan (2013), which also included 5 effort items. Participants rated statements on how they felt immediately after completing the simulated debate. For example, one authenticity item read, 'I was my true self during the last 20 minutes'. All 15 items were rated on a 7-point Likert scale ranging from 1, (strongly disagree), to 7, (strongly agree) and were interspersed as a single measure. Authenticity $(a=.89)$ and effort $(a=.75)$ demonstrated acceptable internal consistency. They were scored separately as our focus is authenticity, yet they were substantially correlated $(r=$ $.49)$.

\section{State affect}

Affective state after the debate was measured using the Positive and Negative Affect Schedule (PANAS; Watson et al., 1988). Ten adjectives reflecting high arousal positive and 10 high arousal negative affect adjectives were rated on a 1-5 Likert scale. PANAS had good internal consistency for positive items $(a=.92)$ as well as the negative items $(a=.86)$.

\section{Debate questionnaire}

Eight ad hoc questions assessing participants' perceptions of the debate were taken from the Smallenbroek et al. (2017) procedure. Three items related to debate difficulty, one item related to effort, and three items related to whether participants' true beliefs and assigned debate condition matched or were mismatched. Both participant agreement with their assigned debate condition $(a=.73)$ and debate difficulty $(a=.80)$ demonstrated acceptable internal consistency.

\section{Trait affect and life satisfaction}

Although not considered here, participants also completed subjective well-being measures: the Satisfaction with Life Scale (SWLS; Diener et al., 1985) and the Scale of Positive and Negative Experience (SPANE; Diener et al., 2009). 


\section{Results}

\section{Preliminary Analyses}

Pearson correlations conducted on the trait and belief/identity variables revealed small to moderate associations, which suggests that beliefs/identity can be distinct from trait levels (see Table 1). In particular, trait extraversion was correlated $r=-.15$ and $r=.38$ with social identity as an introvert or extravert respectively, consistent with the notion that these are separable constructs.

[Table 1 here]

Independent t-tests were conducted to determine whether state variables varied by condition (See Table 2). There were no statistically significant mean differences and therefore no clear preference for one side of the debate over the other.

[Table 2 here]

Pearson's correlations conducted on state variables were moderate to large in generally expected ways (See Table 3). For example, authenticity is associated with positive affect, but not as strongly as it is associated with debate agreement.

[Table 3 here]

\section{Key Hypotheses}

To test the idea that state authenticity depends on both debate condition and identity, a 2 (binary introvert vs. extravert identity choice) x 2 (pro vs. con debate side) ANOVA was conducted. As predicted, there was a statistically significant interaction on state authenticity, $F(1$, $306)=13.13, p<.001, \eta_{p}{ }^{2}=.041$; participants who identified as introverts reported higher authenticity when arguing against $(M=4.56, S D=0.93)$, rather than for $(M=4.14, S D=1.05)$ 
the value of extraversion, whereas the reverse pattern was true of self-identified extraverts $(M=$ 4.25, $S D=1.13$ vs. $M=4.67, S D=0.79$; see Figure $1 D$ ). Counter-dispositional, or counteridentity, arguments produced low authenticity.

The other key tests of hypotheses involved regression analyses on authenticity, particularly the interaction between debate condition and trait extraversion, and between debate condition and identities. We predicted that the interaction was likely to be present or stronger for identities, compared to the trait. A series of regressions was conducted where the mean-centered individual difference (trait or identity) was entered with a dummy coded condition variable (pro $=1$ ) and a cross-product term created by multiplying them (Full regression tables in Supplement). Simple slopes analyses clarified the form of any interactions (see Figure 1).

When examining trait extraversion, neither the main effects of trait $(b=.10, p=.22)$, condition $(b=-.11 p=.36)$ nor their interaction $(b=.22, p=.18)$ showed significant effects on authenticity, consistent with our (null) prediction. Figure 1A plots the simple slopes, and suggests some possible counter-dispositional authenticity costs, despite the interaction not reaching the $p<.05$ threshold. In contrast, a regression with introvert identity did produce a significant interaction term $(b=-.83, p<.001)$, a non-significant main effect for identity $(b=$ $.17, p=.08)$, and a significant main effect of condition $(b=-.42, p=.004)$ in this subgroup. Figure 1B shows the pattern of the interaction, and as predicted introvert identity was negatively associated with authenticity in the pro condition $(b=-.55 p<.001)$, whereas a reverse, positive association appeared in the con condition $(b=.28, p=.04)$. Finally, we examined identity for participants who self-categorized as extraverts (as seen in Figure 1C), and their interaction $(b=$ $.20, p=.40)$ and main effect of identity $(b=.18, p=.14)$ were non-significant, although the main effect of condition was statistically significant $(b=.42, p=.02)$ in this subgroup. As such, 
having a strong identity as an introvert seems to matter to authenticity more than having a strong identity as an extravert in this context.

Study 1
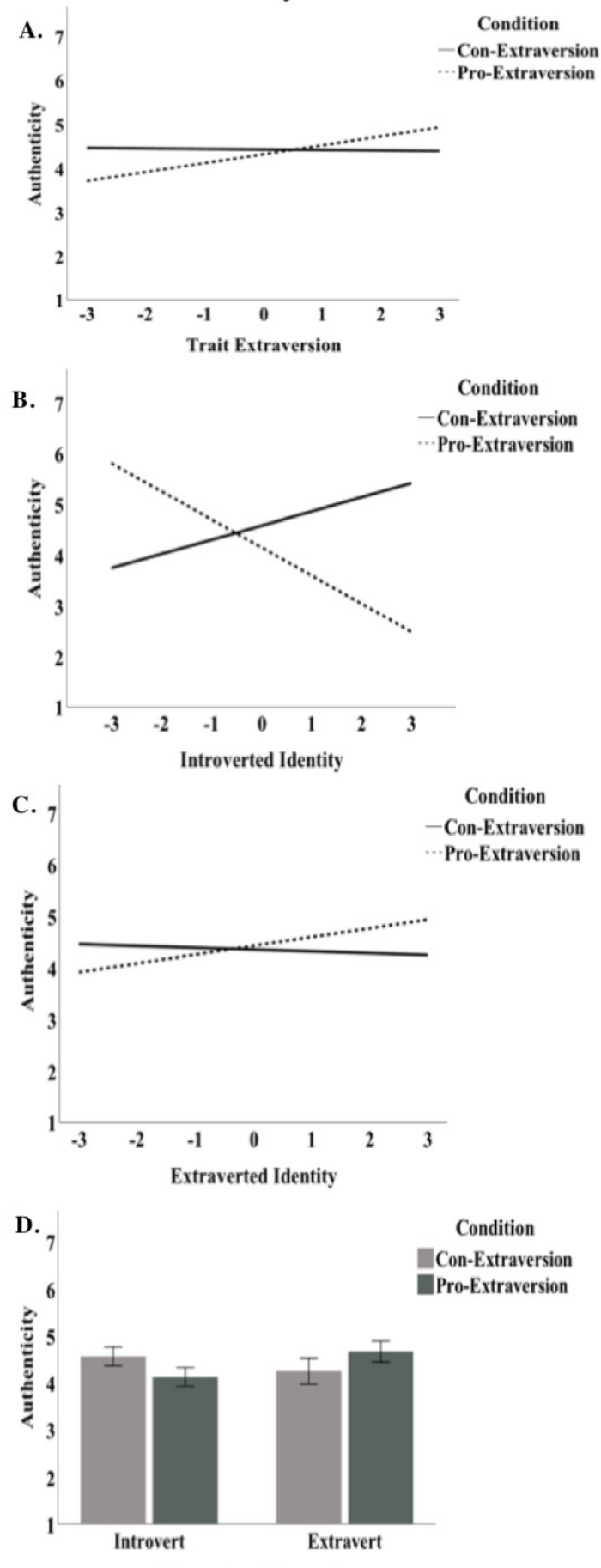

Introvert or Extravert

Error Bars: 95\% Cl

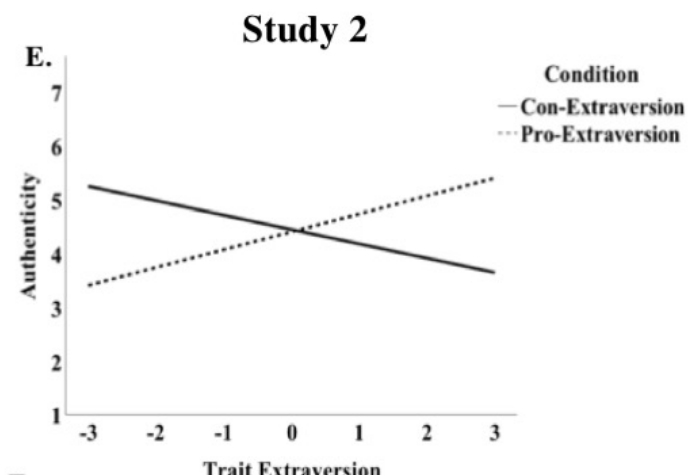

F.
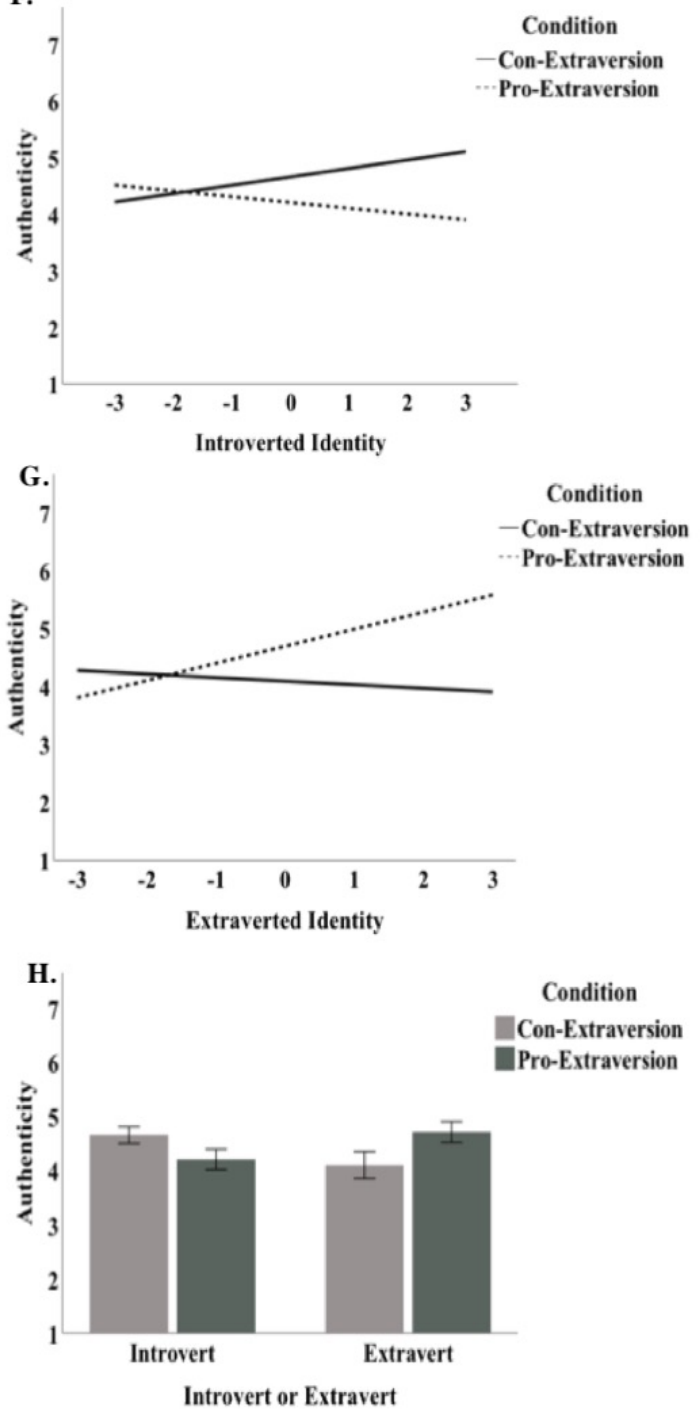

Error Bars: $95 \%$ CI 
Figure 1. The simple slopes for trait extraversion, introversion identity, and extraversion identity on authenticity by condition are depicted in the left panels for Study 1 and in the right panels for Study 2. A bar graph for the binary choice of introverted or extraverted identity on authenticity by condition for Studies 1 and 2 is also shown.

\section{Additional Variables and Considerations}

We explored other individual differences and identity subscales via correlations with authenticity computed separately by experimental condition (see Table 4 and Supplement for subscales); the correlations are akin to simple slopes, and differences in them across conditions are conceptually similar to interactions. Across comparisons, only the introvert identity subscales of intergroup ties and affect produced a statistically significant differences, and in forms similar to the full scale.

[Table 4 here]

We also explored comparisons of correlations by condition for individual difference variables on state positive affect (See Table 5 and Supplement), and generally found a lack of significant interactive patterns, with a few exceptions. Most importantly, positive affect did not show the key interactive pattern between social identity of introversion and condition. This suggests that the 'action' of the introvert identity interaction is with state authenticity and is not just the result of feeling good.

[Table 5 here]

\section{Discussion}

In Study 1 we sought to explore the boundaries of previous research that found high authenticity in dispositional introverts when they behaved in extraverted ways. We did this by 
examining a debate task which asked participants to argue for or against the value of extraversion directly, and by assessing participants' identities as introverts and extraverts. Largely in line with predictions, we found that trait introversion-extraversion did not interact significantly with the debate condition, whereas strong introvert identities were associated with lower authenticity when people argued against their disposition. This suggests that some trait introverts--those who include the trait as part of their core identities--may suffer counterdispositional authenticity costs in ways that are intuitive yet elusive in past empirical work. A key difference here may be that the debate does not invoke clearly counter-dispostional behavior. Of course there are important study limitations and thus caveats to this conclusion. Notably, our key hypotheses come in the context of many other collected measures, and interactions are, in general, notoriously unstable. As such, this could increase the chance of finding some false positive (or negative) results. Therefore, we present a direct replication before taking conclusions from Study 1 alone. We pre-registered the replication study at https://osf.io/8mucf/?view_only=e09702049be44c34b2b465f8cf3ec5d6.

\section{Study 2: Direct replication study}

\section{Methods}

\section{Participants}

We aimed to recruit about 500 participants based on power analysis suggesting $~ 95 \%$ power to replicate the ANOVA (condition $\mathrm{x}$ identity choice) interaction ( $n=409$ needed after exclusions), and the regression introvert-identity $\mathrm{x}$ condition interaction ( $n=170$ who identify as introverts needed) on state authenticity. We recruited 517 people in fall 2020, and excluded 68 participants who spent less than 10 minutes or more than 75 minutes on the study, 25 participants due to inadequate responses on the simulated debate task, 17 participants due to missing data. Of 
the remaining 407 participants included in analyses, the majority were female $(77.9 \%)$, the mean age was 20.06, and $n=248$ identified as an introvert (pro-extraversion condition $=116$, conextraversion condition $=132$ ) and $n=159$ identified as an extravert (pro-extraversion condition $=89$, con-extraversion condition $=70$ ).

\section{Procedure and materials}

The procedure and materials were identical to study one. Internal consistency did not vary significantly for the variables of interest in Study 2 (i.e., trait extraversion $a=.86$, introvert identity $a=.71$, extravert identity $a=.81$, state authenticity $a=.88$, PANAS positive affect $a=$ .91$, PANAS negative affect $a=.88)$.

\section{Results}

\section{Preliminary Analyses}

In line with the findings from Study 1, the Pearson's correlations conducted on the trait and belief/identity variables revealed small to moderate correlations, which suggests that beliefs/identity can be distinct from trait levels (See Table 6).

[Table 6 here]

Independent t-tests were conducted to determine whether state variables varied by condition (See Table 7). Similarly to Study 1, there were not statistically significant mean differences among many state variables; however, debate agreement and debate ease were significantly higher in the pro-extraversion condition of Study 2.

[Table 7 here]

Pearson's correlations conducted on state variables were small to moderate in generally expected ways, similar to Study 1 (See Table 8). 
[Table 8 here]

\section{Key Hypotheses}

A 2 (binary introvert vs. extravert identity choice) x 2 (pro vs. con debate side) ANOVA was conducted to test whether state authenticity depended on both debate condition and identity choice. As in Study 1, there was a statistically significant interaction on state authenticity, $F(1$, $403)=29.39, p<.001, \eta_{p}{ }^{2}=.068$; participants who identified as introverts reported higher authenticity when arguing against $(M=4.66, S D=0.89)$, rather than for $(M=4.21, S D=1.03)$ the value of extraversion, whereas the reverse pattern was true of self-identified extraverts $(M=$ 4.10, $S D=1.04$ vs. $M=4.71, S D=0.92$; See Figure $1 \mathrm{H})$.

As in Study 1, a series of regressions was conducted to test other interactions. When examining trait extraversion, neither the main effects of trait $(b=.05, p=.44)$ or condition $(b=$ $.05, p=.65)$ showed significant effects on authenticity; however, the interaction was statistically significant $(b=.60, p<.001)$, contrary to our findings in Study 1 (see Figure 1E). Trait extraversion was positively associated with authenticity in the pro condition $(b=.33, p<.001)$ and negatively associated with authenticity in the con condition $(b=-.27, p=.01)$. Also in contrast to our findings from Study 1, the interaction term was non-significant in the introvert identity analysis $(b=-.25, p=.11)$; the regression also produced a non-significant main effect for identity $(b=.04, p=.60)$ and a significant main effect of condition $(b=-.45, p<.001)$. Figure $1 \mathrm{~F}$ shows the pattern of the interaction, and although not below the $p<.05$ threshold, introvert identity showed a negative association pattern with authenticity in the pro condition $(b$ $=-.10, p=.38)$, whereas a reverse, positive association pattern in the con condition $(b=.15, p=$ .15). Finally, we examined identity for participants who self-categorized as extraverts (see Figure 
$1 \mathrm{G})$, and the interaction $(b=.36, p=.08)$ and main effect of identity $(b=.10, p=.35)$ were nonsignificant, although the main effect of condition was statistically significant $(b=.60, p<.001)$. Additional Variables and Considerations

As in Study 1, we explored other individual differences and identity subscales via correlations with authenticity computed separately by experimental condition (see Table 9 and Supplement). The introvert identity ingroup affect subscale, pressure to display extraversion, and extraversion deficit-beliefs yielded statistically significant differences in ways that mostly suggested counter-dispositional authenticity costs.

[Table 9 here]

Comparisons of correlations by condition for the trait and belief/identity variables on state positive affect were conducted (see Table 10 and Supplement). A few more significant interactive patterns were found compared to Study 1, however, the z-score values are much smaller with positive affect than they are with authenticity. For example, the largest interactive pattern with positive affect is trait extraversion with $z=2.58$ versus $z=-5.35$ for introvert identity ingroup affect with authenticity. Therefore, it does not seem that positive affect is driving the interactions we found with authenticity.

[Table 10 here]

\section{Discussion}

Study 2 replicated the binary identity by condition effect found in Study 1, suggesting that introvert identities were related to lower authenticity when arguing against their disposition. However, results also diverged from Study 1 as no significant interaction was found between (continuous) introverted identity and debate condition, and trait extraversion did significantly interact with condition to suggest disposition-congruent authenticity benefits. Despite findings 
that contradicted our pre-registered hypotheses in terms of statistical significance, the interaction patterns were descriptively similar across studies (see Figure). Also similar to Study 1, authenticity effects were generally larger and did not closely mirror results for positive affect, suggesting that affect is not the causal force in the debate task. In sum, although significance shifted across trait and social identity variables, both studies found some similar interactive patterns where individual differences seem to matter to authenticity in the debate task such that counter-trait/identity arguments undermine authenticity. Study 2 substantially reduces our confidence that the interactive pattern is exclusive to social identity, however.

\section{General Discussion}

In the two studies presented here, we test the idea that state authenticity may suffer for (some) people when arguing in ways that diverge from their dispositional introversionextraversion. Although intuitive, this idea contrasts with the results of most past research which has typically found that extraverted behavior produces good moods and authenticity for most people, even dispositional introverts. We also proposed that people have identities and beliefs related to their trait extraversion that might be more important to feeling authentic than one's trait levels. Study 1 produced our hypothesized results, with introvert identities mattering more to authenticity than trait extraversion (across debate conditions); however, the identity interaction was not significant, and we found that trait extraversion was more strongly linked to authenticity, in Study 2.

When participants self-identified as an introvert or extravert in a binary choice we observed a clear, significant cross-over interaction with condition in both studies. Unfortunately, we see this binary choice measure as ambiguous in terms of whether it assesses a trait or an identity better. The choice comes as the first part of our identity measure, and it is self-reported 
in a clear, face-valid way that participants consciously endorse. This differs from a typical trait score which is inferred from responses to indicator items that typically do not name the construct under investigation (e.g., 'is full of energy'). Our participants' views of introversion and extraversion may well differ from the construct used by personality psychologists. As such, the binary choice can be seen as an identification with perceived introversion or extraversion. On the other hand, we asked all participants to make this choice, even if it was not easy. Therefore, the choice does not necessarily represent other important elements of social identity, such as personal centrality and camaraderie with other ingroup members. The questions about strength of identification seem clearly superior as measures of social identity, and these interactions were more variable across studies in terms of statistical significance. As such, we conclude that individual differences (traits and/or identities) seem important to authenticity in this debate, but it is difficult to argue that one is clearly more important than the other.

Despite the differences across studies, nearly every analysis produced a (sometimes nonsignificant) pattern indicative of counter-dispositional authenticity costs. This is still unique compared to most other work, and suggests that the particular context, the debate task here, may be as important to finding counter-dispositional costs as assessing trait-related identities. Additional research will be needed to adjudicate whether our debate situation is unique, or whether important 'real world' contexts will produce similar results. This is particularly important as psychologists work towards 'acting extraverted' happiness interventions where assigned extraverted behavior might seem inauthentic to some introverts (Jaques-Hamilton et al., 2019; van Allen et al., 2021). A natural extension of this work, then, is to include measures of social identity in future studies of extraverted behavior more specifically. 
Most research on state authenticity finds it covarying with positive affect and otherwise pleasant circumstances. This is also true in the domain of extraversion where some have even suggested that the link between extraverted behavior and authenticity is explained (mediated) by positive affect (Wilt et al., 2021). The debate procedure seems to largely dissociate good feelings from authenticity; we found authenticity interactions between individual differences and debate condition that did not appear for positive affect. These authenticity findings do not seem driven by affect. This argues against a strong view that feeling authentic is merely feeling good or only occurs in pleasant circumstances. Also, the useful adaptation of the debate procedure to this new context recommends it as a potentially useful tool to study state authenticity in other domains.

As with all research, our studies had some limitations that must be considered when interpreting the results. For example, we were limited by samples that consisted of university students who differ from the general population in many ways. Notable among them is developmental age, where typical university students are still undergoing identity formation, and this may impact how they think about and value their trait extraversion and identity. Specifically, it is possible that the results would be stronger with an older sample that has already undergone identity formation compared to younger people. Given the limitations of the convenience samples used here, caution should be used before generalizing beyond highly similar groups, and future research should be conducted with different groups or more representative samples.

A second limitation of our studies is that Study 1 was conducted before the COVID-19 pandemic restrictions began in the Winter of 2020 and Study 2 was conducted during the COVID-19 pandemic in the Fall of 2020. In the Fall of 2020 all university courses were online and there were major restrictions on all social gatherings and daily activities. Therefore, it is possible the social isolation participants experienced prompted them to think about their 
introversion-extraversion differently. For example, perhaps some people who thought they were high on extraversion enjoyed the social isolation more than they anticipated or some highly identified introverts began to question their traits when social obligations were removed. It is possible that the different social contexts of Study 1 and 2 account for the divergent results (i.e., significant interactions moved from identity to traits). Although possible, the salience of the pandemic does not mean that it is responsible for differences across studies, and we are not aware of evidence that trait scores shifted more during the pandemic. It seems reasonable to attribute differences across studies to other causes, particularly sampling error as interactions are notoriously unstable and our sample sizes are not enormous.

A third limitation of our research was the online debate procedure. The online debate procedure instructed participants to respond to statements about the benefits of extraversion in either an pro-extraversion or con-extraversion stance. This debate creates a clear conflict between personality and instructions, but it was unable to test extraverted behavior per se, which is how the majority of the past research on the relationship between extraversion and authenticity has been tested. Indeed, the online debate might be described as introverted behavior in both conditions due to the lack of face-to-face contact, or, alternatively, as extraverted behavior due to the need to assert an argument, etc.. Therefore, a useful future direction will be to extend social identity measures to designs that include variations in extraverted behavior specifically, such as instructing participants to act extraverted or introverted, or that assess natural behavioral variation across contexts with experience sampling. Notably, one of the only studies that suggested inauthenticity could stem from counter-dispositional manipulated extraversion assessed this in daily life, across many contexts (Jaques-Hamilton et al., 2019). Although we did not expect to find interactions with trait extraversion (as in Study 2), it is worth considering 
whether our debate context is particularly unusual, or if the limited contexts of previous experimental studies (typically in labs with strangers) lack broad generalizability (cf. Whelan, 2013).

Details of the debate itself might also be altered to explore the robustness and the principles driving effects. For example, the debate resolution used the phrasing "It is good to be more extraverted than introverted," as we designed the research with strongly identified introverts in mind. Future research might assess whether debating for the other side, namely that "it is good to be more introverted than extraverted", influences state authenticity in a similar way. This mirrored version may produce conceptually similar results for those with extravert identities, but it is worth noting that the social desirability and usefulness differ between the introverted and extraverted polls of the dimension, potentially changing the implications for state authenticity and disposition or identity interactions. Finally, it is also possible that the online debate procedure was susceptible to demand effects as the true purpose of the study was not purposefully masked from the participants. For example, participants explicitly self-reported their dispositions and identities, perhaps making them salient, just before the debate about extraversion.

Overall, we found a pattern of results that suggests that trait extraversion and identification as an introvert or extravert can interact to create disposition-congruent (in)authenticity. We predicted that only identity, and not trait extraversion, would yield significant interactions; however, that was not clearly the case. The ambiguous binary choice between 'introvert' and 'extravert' was the only measure that replicated across both studies, whereas the interactive patterns for both trait and identity measures were inconsistently significant, if conceptually similar in form. Future research should be directed at determining 
where identity versus trait extraversion is stronger to further unpack the less typical interactive pattern observed in these studies. Despite some study limitations, the current research suggests that trait extraversion and beliefs/identities about extraversion can affect authenticity in some contexts, and in ways that do not closely follow positive affect. 


\section{References}

Cain, S. (2012). Quiet: The power of introverts in a world that can't stop talking. London: Penguin Books.

Cameron, J. E. (2004). A three-factor model of social identity. Self and Identity, 3(3), 239-262. doi: https://doi.org/10.1080/13576500444000047.

Ching, C. M., Church, A. T., Katigbak, M. S., Reyes, J. A. S., Tanaka-Matsumi, J., Takaoka, S., ... \& Ortiz, F. A. (2014). The manifestation of traits in everyday behavior and affect: A five-culture study. Journal of Research in Personality, 48, 1-16. doi: https://doi.org/10.1016/j.jrp.2013.10.002.

Christy, A. G., Seto, E., Schlegel, R. J., Vess, M., \& Hicks, J. A. (2016). Straying from the righteous path and from ourselves: The interplay between perceptions of morality and self-knowledge. Personality and Social Psychology Bulletin, 42(11), 1538-1550. doi: https://doi.org/10.1177/0146167216665095.

Cooper, A. B., Sherman, R. A., Rauthmann, J. F., Serfass, D. G., \& Brown, N. A. (2018).

Feeling good and authentic: Experienced authenticity in daily life is predicted by positive feelings and situation characteristics, not trait-state consistency. Journal of Research in Personality, 77, 57-69. doi: https://doi.org/10.1016/j.jrp.2018.09.005

Diener, E., Emmons, R. A., Larsen, R. J., \& Griffin, S. (1985). The Satisfaction with Life Scale. Journal of Personality Assessment, 49, 71-75. doi: https://doi.org/10.1207/s15327752jpa4901_13

Diener, E., Wirtz, D., Tov, W., Kim-Prieto, C., Choi. D., Oishi, S., \& Biswas-Diener, R. (2009). New measures of well-being: Flourishing and positive and negative feelings. Social Indicators Research, 39, 247-266. doi: 10.1007/978-90-481-2354-4 12 
Fleeson, W. (2004). Moving personality beyond the person-situation debate: The challenge and the opportunity of within-person variability. Current Directions in Psychological Science, 13(2), 83-87. doi: 10.1111/j.0963-7214.2004.00280.x

Fleeson, W., \& Wilt, J. (2010). The relevance of big five trait content in behavior to subjective authenticity: Do high levels of within-person behavioral variability undermine or enable authenticity achievement?. Journal of Personality, 78 (4), 1353-1382. doi: 10.1111/j.1467-6494.2010.00653.x.

Heppner, W. L., Kernis, M. H., Lakey, C. E., Campbell, W. K., Goldman, B. M., Davis, P. J., \& Cascio, E. V. (2008). Mindfulness as a means of reducing aggressive behavior: dispositional and situational evidence. Aggressive behavior, 34(5), 486-496. https://doi.org/10.1002/ab.20258

Huta, V., \& Waterman, A. S. (2014). Eudaimonia and its distinction from hedonia: Developing a classification and terminology for understanding conceptual and operational definitions. Journal of Happiness Studies, 15, 1425-1456. doi: 10.1007/s10902-013-9485-0

Jacques-Hamilton, R., Sun, J., \& Smillie, L. D. (2019). Costs and benefits of acting extraverted: A randomized controlled trial. Journal of Experimental Psychology: General, 148(9), 1538-1556.

Jongman-Sereno, K. P., \& Leary, M. R. (2020). Self-judgments of authenticity. Self and Identity, 19(1), 32-63. doi: https://doi.org/10.1080/15298868.2018.1526109

Kernis, M. H., \& Goldman, B. M. (2006). A multicomponent conceptualization of authenticity: Theory and research. In M. P. Zanna (Ed.), Advances in experimental social psychology (pp. 284-357). San Diego, CA: Elsevier Academic Press. 
Lawn, R. B., Slemp, G. R., \& Vella-Brodrick, D. A. (2018). Quiet flourishing: The authenticity and well-being of trait introverts living in the west depends on extraversion-deficit beliefs. Journal of Happiness Studies, 1-21. doi: 10.1007/s10902-018-0037-5.

Leikas, S., Kuula, L., \& Pesonen, A. K. (2021). Does counter-habitual behavior carry psychological costs? Journal of Research in Personality, 92, 104077. doi: https://doi.org/10.1016/j.jrp.2021.104077

Lenton, A. P., Bruder, M., Slabu, L., \& Sedikides, C. (2013). How does “being real” feel? The experience of state authenticity. Journal of Personality, 81, 276-289. doi: 10.1111/j.14676494.2012.00805.x.

McCabe, K. O., \& Fleeson, W. (2012). What is extraversion for? Integrating trait and motivational perspectives and identifying the purpose of extraversion. Psychological Science, 23(12), 1498-1505. doi: 10.1177/0956797612444904

Rivera, G. N., Christy, A. G., Kim, J., Vess, M., Hicks, J. A., \& Schlegel, R. J. (2019). Understanding the relationship between perceived authenticity and well-being. Review of General Psychology, 23(1), 113-126. doi: https://doi.org/10.1037/gpr0000161

Schlegel, R. J., \& Hicks, J. A. (2011). The true self and psychological health: Emerging evidence and future directions. Social and Personality Psychology Compass, 5(12), 989-1003. doi: https://doi.org/10.1111/j.1751-9004.2011.00401.x

Schmader, T., \& Sedikides, C. (2018). State authenticity as fit to environment: The implications of social identity for fit, authenticity, and self-segregation. Personality and Social Psychology Review, 22(3), 228-259. doi: 10.1177/1088868317734080 
Sedikides, C., Slabu, L., Lenton, A., \& Thomaes, S. (2017). State authenticity. Current Directions in Psychological Science, 26(6), 521-525. doi: https://doi.org/10.1177/0963721417713296.

Sheldon, K. M., Ryan, R. M., Rawsthorne, L. J., \& Ilardi, B. (1997). Trait self and true self: Cross-role variation in the Big-Five personality traits and its relations with psychological authenticity and subjective well-being. Journal of Personality and Social Psychology, 73(6), 1380. doi: 10.1037/0022-3514.73.6.1380.

Smallenbroek, O., Zelenski, J. M., \& Whelan, D. C. (2017). Authenticity as a eudaimonic construct: The relationships among authenticity, values, and valence. The Journal of Positive Psychology, 12(2), 197-209. doi: 10.1080/17439760.2016.1187198.

Soto, C. J., \& John, O. P. (2017). Short and extra-short forms of the Big Five Inventory-2: The BFI-2-S and BFI-2-XS. Journal of Research in Personality, 68, 69-81. doi: http://dx.doi.org/10.1016/j.jrp.2017.02.004

Strohminger, N., Knobe, J., \& Newman, G. (2017). The true self: A psychological concept distinct from the self. Perspectives on Psychological Science, 12(4), 551-560. doi: https://doi.org/10.1177/1745691616689495

Tajfel, H. (Ed.) (1978). Differentiation Between Social Groups: Studies in the Social Psychology of Intergroup Relations. London: Academic Press.

Tajfel, H., \& Turner, J. C. (1979). An integrative theory of intergroup conflict. In W. G. Austin \& S. Worchel (Eds.), The Social Psychology of Intergroup Relations (pp. 33-47). Monterey, CA: Brooks/Cole. 
van Allen, Z. M., Walker, D. L., Streiner, T., \& Zelenski, J. M. (2021). Enacted extraversion as a well-being enhancing strategy in everyday life: Testing across three, week-long interventions. Collabra: Psychology, 7(1), 29931. https://doi.org/10.1525/collabra.29931

Watson, D., Clark, L. A., \& Tellegen, A. (1988). Development and validation of brief measures of positive and negative affect: The PANAS scales. Journal of Personality and Social Psychology, 54(6), 1063. doi: https://doi.org/10.1037/0022-3514.54.6.1063

Whelan, D. C. (2013). Extraversion and counter-dispositional behaviour: Exploring consequences and the impact of situation-behaviour congruence. Doctoral dissertation, Carleton University Ottawa, Canada. doi: https://doi.org/10.22215/etd/2014-10091

Wilt, J. A., Sun, J., Jacques-Hamilton, R., \& Smillie, L. D. (2021, March 19). Why Does it Feel Authentic to be and act Extraverted? Exploring the Mediating Role of Positive Affect. https://doi.org/10.31234/osf.io/7mj6g

Wood, A, M., Linley, P. A., Maltby, J. Baliousis, M. Joseph, S. (2008). The authentic personality: A theoretical and empirical conceptualization and the development of the Authenticity Scale. Journal of Counseling Psychology, 55(3), 385-399. doi: https://doi.org/10.1037/0022-0167.55.3.385 
Table 1

Pearson Correlations Among Individual Differences (Study 1)

\begin{tabular}{|c|c|c|c|c|c|c|c|}
\hline & 1. & 2. & 3. & 4. & 5. & 6. & 7. \\
\hline $\begin{array}{l}\text { 1. Trait } \\
\text { Extraversion }\end{array}$ & & & & & & & \\
\hline $\begin{array}{l}\text { 2. Social } \\
\text { Identity } \\
\text { Choice (Intro } \\
\text { or Extra) }\end{array}$ & $\begin{array}{l}.64 * * \\
(.59, .70)\end{array}$ & & & & & & \\
\hline $\begin{array}{l}\text { 3. Social } \\
\text { Identity } \\
\text { (Intro) }\end{array}$ & $\begin{array}{l}-.15^{*} \\
(-.30, .01)\end{array}$ & - & & & & & \\
\hline $\begin{array}{l}\text { 4. Social } \\
\text { Identity } \\
\text { (Extra) }\end{array}$ & $\begin{array}{l}.38 * \\
(.17, .55)\end{array}$ & - & - & & & & \\
\hline $\begin{array}{l}\text { 5. Cultural } \\
\text { Value }\end{array}$ & $\begin{array}{l}.22 * * \\
(.10, .33)\end{array}$ & $\begin{array}{l}.17 * * \\
(.07, .26)\end{array}$ & $\begin{array}{l}-.09 \\
(-.22, .05)\end{array}$ & $\begin{array}{l}.21 * \\
(-.02, .40)\end{array}$ & & & \\
\hline $\begin{array}{l}\text { 6. Pressure to } \\
\text { Display Extra }\end{array}$ & $\begin{array}{l}.26 * * \\
(.15, .36)\end{array}$ & $\begin{array}{l}.23^{* *} \\
(.12, .32)\end{array}$ & $\begin{array}{l}-.06 \\
(-.20, .07)\end{array}$ & $\begin{array}{l}.17 \\
(-.05, .38)\end{array}$ & $\begin{array}{l}.44 * * \\
(.34, .54)\end{array}$ & & \\
\hline $\begin{array}{l}\text { 7. Extra- } \\
\text { Deficit } \\
\text { Beliefs }\end{array}$ & $\begin{array}{l}-.55 * * \\
(-.62,-.47)\end{array}$ & $\begin{array}{l}-.56 * * \\
(-.63,-.49)\end{array}$ & $\begin{array}{l}-.21 * * \\
(-.36,-.07)\end{array}$ & $\begin{array}{l}.12 \\
(-.06, .28)\end{array}$ & $\begin{array}{l}-.17 * * \\
(-.28,-.04)\end{array}$ & $\begin{array}{l}-.17 * * \\
(-.27,-.05)\end{array}$ & \\
\hline
\end{tabular}

Note: $* p<.05, * * p<.01$.

95\% confidence intervals from bootstrapping are below the correlation coefficients. 
Table 2

Mean Condition Differences Between State Affect (PANAS), State Authenticity, Debate Agreement, and Debate Ease with t-tests (Study 1)

\begin{tabular}{|c|c|c|c|c|c|c|}
\hline \multirow[t]{2}{*}{ Variable } & \multicolumn{2}{|c|}{ Pro-extraversion } & \multicolumn{2}{|c|}{ Con-extraversion } & \multirow[t]{2}{*}{ t-test } & \multirow[t]{2}{*}{$d$} \\
\hline & $M$ & $S D$ & $M$ & $S D$ & & \\
\hline PANAS (PA) & 2.42 & .89 & 2.27 & .94 & -1.38 & 0.16 \\
\hline PANAS (NA) & 1.53 & .57 & 1.44 & .57 & -1.42 & 0.16 \\
\hline State Authenticity & 4.30 & 1.00 & 4.43 & 1.03 & 1.12 & 0.13 \\
\hline Debate Agreement & 4.70 & 1.34 & 4.48 & 1.52 & -1.35 & 0.15 \\
\hline Debate Ease & 4.54 & 1.51 & 4.35 & 1.44 & -1.12 & 0.13 \\
\hline
\end{tabular}


Table 3

Pearson Correlations Among State Affect (PANAS), State Authenticity, Debate Agreement, and Debate Ease (Study 1)

\begin{tabular}{|c|c|c|c|c|c|c|}
\hline Variable & Mean (SD) & 1. & 2. & 3. & 4. & 5. \\
\hline 1. PANAS (PA) & $2.35(0.92)$ & & & & & \\
\hline 2. PANAS (NA) & $1.48(0.57)$ & $\begin{array}{l}.08 \\
(-.02, .19)\end{array}$ & & & & \\
\hline 3. State Authenticity & $4.36(1.02)$ & $\begin{array}{l}.31 * * \\
(.22, .41)\end{array}$ & $\begin{array}{l}-.22 * * \\
(-.31,-.12)\end{array}$ & & & \\
\hline 4. Debate Agreement & $4.59(1.43)$ & $\begin{array}{l}.30 * * \\
(.20, .40)\end{array}$ & $\begin{array}{l}-.20 * * \\
(-.30,-.11)\end{array}$ & $\begin{array}{l}.66^{* *} \\
(.59, .73)\end{array}$ & & \\
\hline 5. Debate Ease & $4.45(1.47)$ & $\begin{array}{l}.18^{* *} \\
(.06, .29)\end{array}$ & $\begin{array}{l}-.26 * * \\
(-.36,-.15)\end{array}$ & $\begin{array}{l}.50 * * \\
(.40, .59)\end{array}$ & $\begin{array}{l}.58 * * \\
(.50, .66)\end{array}$ & \\
\hline
\end{tabular}

Note: $* p<.05, * * p<.01$

95\% confidence intervals from bootstrapping are below the correlation coefficients. 
Table 4

Pearson Correlations between Individual Differences and State Authenticity by Condition (Study

1)

\begin{tabular}{|c|c|c|c|}
\hline Variable & Pro-extraversion $r$ & Con-extraversion $r$ & z-test \\
\hline Trait Extraversion & $\begin{array}{l}.15(\mathrm{n}=158) \\
(-.02, .30)\end{array}$ & $\begin{array}{l}-.01(\mathrm{n}=152) \\
(-.17, .16)\end{array}$ & 1.41 \\
\hline $\begin{array}{l}\text { Social Identity Choice } \\
(\text { Intro }=1 \text { or Extra }=2)\end{array}$ & $\begin{array}{l}.25 * *(\mathrm{n}=158) \\
(.12, .38)\end{array}$ & $\begin{array}{l}-.15(\mathrm{n}=152) \\
(-.31, .02)\end{array}$ & $3.54 * *$ \\
\hline Social Identity (Intro) & $\begin{array}{l}-.39 * *(\mathrm{n}=108) \\
(-.54,-.22)\end{array}$ & $\begin{array}{l}.23^{*}(\mathrm{n}=85) \\
(.04, .40)\end{array}$ & $-4.38 * *$ \\
\hline Social Identity (Extra) & $\begin{array}{l}.30 *(\mathrm{n}=50) \\
(-.08, .63)\end{array}$ & $\begin{array}{l}.04(\mathrm{n}=67) \\
(-.21, .28)\end{array}$ & 1.40 \\
\hline Cultural Value & $\begin{array}{l}.18 *(\mathrm{n}=158) \\
(.01, .35)\end{array}$ & $\begin{array}{l}.10(\mathrm{n}=152) \\
(-.06, .28)\end{array}$ & 0.71 \\
\hline Pressure to Display Extra & $\begin{array}{l}.03(\mathrm{n}=158) \\
(-.13, .17)\end{array}$ & $\begin{array}{l}-.15(\mathrm{n}=152) \\
(-.33, .05)\end{array}$ & 1.58 \\
\hline Extra-Deficit Beliefs & $\begin{array}{l}.05(\mathrm{n}=158) \\
(-.09, .19)\end{array}$ & $\begin{array}{l}.05(\mathrm{n}=152) \\
(-.13, .22)\end{array}$ & 0 \\
\hline
\end{tabular}

Note: $* p<.05, * * p<.01$

95\% confidence intervals from bootstrapping are below the correlation coefficients. 
Table 5

Pearson Correlations between Individual Differences and State Positive Affect by Condition (Study 1)

\begin{tabular}{|c|c|c|c|}
\hline Variable & Pro-extraversion $r$ & Con-extraversion $r$ & z-test \\
\hline Trait Extraversion & $\begin{array}{l}.22 * *(\mathrm{n}=158) \\
(.02, .41)\end{array}$ & $\begin{array}{l}.19 *(\mathrm{n}=152) \\
(.03, .34)\end{array}$ & 0.27 \\
\hline $\begin{array}{l}\text { Social Identity Choice } \\
(\text { Intro }=1 \text { or Extra }=2)\end{array}$ & $\begin{array}{l}.16(\mathrm{n}=158) \\
(-.01, .31)\end{array}$ & $\begin{array}{l}.01(\mathrm{n}=152) \\
(-.17, .16)\end{array}$ & 1.32 \\
\hline Social Identity (Intro) & $\begin{array}{l}.11(\mathrm{n}=108) \\
(-.09, .30)\end{array}$ & $\begin{array}{l}.17(\mathrm{n}=85) \\
(-.09, .42)\end{array}$ & -0.42 \\
\hline Social Identity (Extra) & $\begin{array}{l}.66^{* *}(\mathrm{n}=50) \\
(.50, .79)\end{array}$ & $\begin{array}{l}.20(\mathrm{n}=67) \\
(-.11, .44)\end{array}$ & $3.07 * *$ \\
\hline Cultural Value & $\begin{array}{l}.05(\mathrm{n}=158) \\
(-.12, .22)\end{array}$ & $\begin{array}{l}.09(\mathrm{n}=152) \\
(-.06, .24)\end{array}$ & -0.35 \\
\hline Pressure to Display Extra & $\begin{array}{l}-.02(\mathrm{n}=158) \\
(-.19, .17)\end{array}$ & $\begin{array}{l}-.05(\mathrm{n}=152) \\
(-.25, .14)\end{array}$ & 0.26 \\
\hline Extra-Deficit Beliefs & $\begin{array}{l}-.08(\mathrm{n}=158) \\
(-.27, .12)\end{array}$ & $\begin{array}{l}-.05(\mathrm{n}=152) \\
(-.22, .12)\end{array}$ & 0.26 \\
\hline
\end{tabular}

Note: $* p<.05, * * p<.01$

$95 \%$ confidence intervals from bootstrapping are below the correlation coefficients. 
Table 6

Pearson Correlations Among Individual Differences (Study 2)

\begin{tabular}{|c|c|c|c|c|c|c|c|}
\hline & 1. & 2. & 3. & 4. & 5. & 6. & 7. \\
\hline $\begin{array}{l}\text { 1. Trait } \\
\text { Extraversion }\end{array}$ & & & & & & & \\
\hline $\begin{array}{l}\text { 2. Social } \\
\text { Identity } \\
\text { Choice (Intro } \\
\text { or Extra) }\end{array}$ & $\begin{array}{l}.64 * * \\
(.59, .69)\end{array}$ & & & & & & \\
\hline $\begin{array}{l}\text { 3. Social } \\
\text { Identity } \\
\text { (Intro) }\end{array}$ & $\begin{array}{l}-.08 \\
(-.19, .05)\end{array}$ & - & & & & & \\
\hline $\begin{array}{l}\text { 4. Social } \\
\text { Identity } \\
\text { (Extra) }\end{array}$ & $\begin{array}{l}.42 * * \\
(.23, .57)\end{array}$ & - & - & & & & \\
\hline $\begin{array}{l}\text { 5. Cultural } \\
\text { Value }\end{array}$ & $\begin{array}{l}.18 * * \\
(.07, .28)\end{array}$ & $\begin{array}{l}.17^{* *} \\
(.08, .25)\end{array}$ & $\begin{array}{l}-.06 \\
(-.19, .08)\end{array}$ & $\begin{array}{l}.29 * * \\
(.13, .43)\end{array}$ & & & \\
\hline $\begin{array}{l}\text { 6. Pressure to } \\
\text { Display Extra }\end{array}$ & $\begin{array}{l}.38 * * \\
(.27, .47)\end{array}$ & $\begin{array}{l}.27^{* *} \\
(.18, .35)\end{array}$ & $\begin{array}{l}-.06 \\
(-.20, .08)\end{array}$ & $\begin{array}{l}.31 * * \\
(.13, .45)\end{array}$ & $\begin{array}{l}.38 * * \\
(.26, .49)\end{array}$ & & \\
\hline $\begin{array}{l}\text { 7. Extra- } \\
\text { Deficit } \\
\text { Beliefs }\end{array}$ & $\begin{array}{l}-.53 * * \\
(-.60,-.46)\end{array}$ & $\begin{array}{l}-.52 * * \\
(-.58,-.46)\end{array}$ & $\begin{array}{l}-.07 \\
(-.19, .07)\end{array}$ & $\begin{array}{l}.20 * \\
(.02, .35)\end{array}$ & $\begin{array}{l}.03 \\
(-.07, .13)\end{array}$ & $\begin{array}{l}-.05 \\
(-.16, .07)\end{array}$ & \\
\hline
\end{tabular}

Note: $* p<.05, * * p<.01$

95\% confidence intervals from bootstrapping are below the correlation coefficients. 
Table 7

Mean Condition Differences Between State Affect (PANAS), State Authenticity, Debate Agreement, and Debate Ease with t-tests (Study 2)

\begin{tabular}{|c|c|c|c|c|c|c|}
\hline \multirow[t]{2}{*}{ Variable } & \multicolumn{2}{|c|}{ Pro-extraversion } & \multicolumn{2}{|c|}{ Con-extraversion } & \multirow[t]{2}{*}{$\mathrm{t}$-test } & \multirow[t]{2}{*}{$d$} \\
\hline & $M$ & $S D$ & $M$ & $S D$ & & \\
\hline PANAS (PA) & 2.58 & .95 & 2.41 & .84 & -1.87 & 0.19 \\
\hline PANAS (NA) & 1.55 & .69 & 1.46 & .54 & -1.51 & 0.15 \\
\hline State Authenticity & 4.43 & 1.01 & 4.46 & 1.00 & 0.39 & 0.04 \\
\hline Debate Agreement & 5.00 & 1.38 & 4.56 & 1.46 & $-3.11 * *$ & 0.31 \\
\hline Debate Ease & 4.90 & 1.39 & 4.39 & 1.42 & $-3.68 * *$ & 0.36 \\
\hline
\end{tabular}


Table 8

Pearson Correlations Among State Affect (PANAS), State Authenticity, Debate Agreement, and Debate Ease (Study 2)

\begin{tabular}{|c|c|c|c|c|c|c|}
\hline Variable & Mean (SD) & 1. & 2. & 3. & 4. & 5. \\
\hline 1. PANAS (PA) & $2.50(0.90)$ & & & & & \\
\hline 2. PANAS (NA) & $1.51(0.62)$ & $\begin{array}{l}.03 \\
(-.07, .11)\end{array}$ & & & & \\
\hline 3. State Authenticity & $4.45(0.99)$ & $\begin{array}{l}.35^{* *} \\
(.26, .43)\end{array}$ & $\begin{array}{l}-.14 * * \\
(-.22,-.05)\end{array}$ & & & \\
\hline 4. Debate Agreement & $4.78(1.43)$ & $\begin{array}{l}.27 * * \\
(.18, .35)\end{array}$ & $\begin{array}{l}-.14 * * \\
(-.24,-.05)\end{array}$ & $\begin{array}{l}.63^{* *} \\
(.55, .70)\end{array}$ & & \\
\hline 5. Debate Ease & $4.65(1.42)$ & $\begin{array}{l}.21 * * \\
(.11, .30)\end{array}$ & $\begin{array}{l}-.17 * * \\
(-.26,-.06)\end{array}$ & $\begin{array}{l}.44^{* *} \\
(.34, .53)\end{array}$ & $\begin{array}{l}.64 * * \\
(.57, .70)\end{array}$ & \\
\hline
\end{tabular}

Note: $* p<.05, * * p<.01$

95\% confidence intervals from bootstrapping are below the correlation coefficients. 
Table 9

Pearson Correlations between Individual Differences and State Authenticity by Condition (Study

2)

\begin{tabular}{|c|c|c|c|}
\hline Variable & Pro-extraversion $r$ & Con-extraversion $r$ & z-test \\
\hline Trait Extraversion & $\begin{array}{l}.25^{* *}(\mathrm{n}=205) \\
(.10, .38)\end{array}$ & $\begin{array}{l}-.19 * *(\mathrm{n}=202) \\
(-.33,-.04)\end{array}$ & $4.48 * *$ \\
\hline $\begin{array}{l}\text { Social Identity Choice } \\
(\text { Intro }=1 \text { or Extra }=2)\end{array}$ & $\begin{array}{l}.25 * *(\mathrm{n}=205) \\
(.12, .37)\end{array}$ & $\begin{array}{l}-.27 * *(\mathrm{n}=202) \\
(-.41,-.13)\end{array}$ & $5.33 * *$ \\
\hline Social Identity (Intro) & $\begin{array}{l}-.08(\mathrm{n}=116) \\
(-.26, .13)\end{array}$ & $\begin{array}{l}.14(\mathrm{n}=132) \\
(-.05, .32)\end{array}$ & $-1.72 *$ \\
\hline Social Identity (Extra) & $\begin{array}{l}.22 *(n=89) \\
(-.01, .44)\end{array}$ & $\begin{array}{l}-.05(\mathrm{n}=70) \\
(-.31, .22)\end{array}$ & 1.68 \\
\hline Cultural Value & $\begin{array}{l}.10(\mathrm{n}=205) \\
(-.05, .23)\end{array}$ & $\begin{array}{l}-.02(\mathrm{n}=202) \\
(-.14, .11)\end{array}$ & 1.21 \\
\hline Pressure to Display Extra & $\begin{array}{l}.23 * *(\mathrm{n}=205) \\
(.08, .37)\end{array}$ & $\begin{array}{l}-.05(\mathrm{n}=202) \\
(-.18, .09)\end{array}$ & $2.85 * *$ \\
\hline Extra-Deficit Beliefs & $\begin{array}{l}-.18 *(\mathrm{n}=205) \\
(-.32,-.03)\end{array}$ & $\begin{array}{l}.16^{*}(\mathrm{n}=202) \\
(.00, .29)\end{array}$ & $-3.44 * *$ \\
\hline
\end{tabular}

Note: $* p<.05, * * p<.01$

95\% confidence intervals from bootstrapping are below the correlation coefficients. 
Table 10

Pearson Correlations between Individual Differences and State Positive Affect by Condition

(Study 2)

\begin{tabular}{|c|c|c|c|}
\hline Variable & Pro-extraversion $r$ & Con-extraversion $r$ & z-test \\
\hline Trait Extraversion & $\begin{array}{l}.43 * *(\mathrm{n}=205) \\
(.31, .53)\end{array}$ & $\begin{array}{l}.20 *(\mathrm{n}=202) \\
(.05, .34)\end{array}$ & $2.58^{*}$ \\
\hline $\begin{array}{l}\text { Social Identity Choice } \\
(\text { Intro }=1 \text { or Extra }=2)\end{array}$ & $\begin{array}{l}.29 * *(\mathrm{n}=205) \\
(.15, .42)\end{array}$ & $\begin{array}{l}.00(\mathrm{n}=202) \\
(-.13, .15)\end{array}$ & $2.99 * *$ \\
\hline Social Identity (Intro) & $\begin{array}{l}.11(\mathrm{n}=116) \\
(-.06, .29)\end{array}$ & $\begin{array}{l}-.04(\mathrm{n}=132) \\
(-.18, .12)\end{array}$ & 1.17 \\
\hline Social Identity (Extra) & $\begin{array}{l}.36^{* *}(\mathrm{n}=89) \\
(.18, .52)\end{array}$ & $\begin{array}{l}.10(\mathrm{n}=70) \\
(-.11, .32)\end{array}$ & 1.70 \\
\hline Cultural Value & $\begin{array}{l}.04(\mathrm{n}=205) \\
(-.10, .18)\end{array}$ & $\begin{array}{l}-.01(\mathrm{n}=202) \\
(-.13, .12)\end{array}$ & 0.50 \\
\hline Pressure to Display Extra & $\begin{array}{l}.21 * *(\mathrm{n}=205) \\
(.06, .34)\end{array}$ & $\begin{array}{l}.02(\mathrm{n}=202) \\
(-.13, .18)\end{array}$ & $1.93^{*}$ \\
\hline Extra-Deficit Beliefs & $\begin{array}{l}-.24 * *(\mathrm{n}=205) \\
(-.37,-.12)\end{array}$ & $\begin{array}{l}-.10(\mathrm{n}=202) \\
(-.24, .04)\end{array}$ & -1.45 \\
\hline
\end{tabular}

Note: $* p<.05, * * p<.01$

95\% confidence intervals from bootstrapping are below the correlation coefficients. 